\title{
Partitioning Of Energy Balance Components at Different Phenological Stages of Wheat
}

\author{
Smita Gupta ${ }^{1}$, Sumana Roy ${ }^{2}$, \\ Department of Agrometeorology GBPUA\&T Pantnagar-263145
}

\begin{abstract}
A thorough understanding of the radiation balance over a crop canopy and the accurate estimation of different components of net radiation over the crop surface assume a great significance in terrestrial ecosystem. Considering its importance a field experiment was conducted at agricultural farm of GBPUA\&T Pantnagar during rabi season of 2012-13 to estimate partitioning of energy balance components by using Bowen Ratio Energy Balance (BREB) method at different phenological stages of wheat. The BREB method was used to obtain field energy balance, including latent heat flux, soil heat flux. These measurements were coupled with radiation measurement at the soil surface to partition energy balance component at different phenological stages of wheat viz. Crown root initiation (CRI), tillering, jointing, heading, flowering, grain filling, soft dough and hard dough stage. It was found that net radiation (Rn) was the major portion of energy balance component. The values varied between 6.02 to $27.6 \mathrm{MJm}^{-2} d^{-1}$ at various growth stages of wheat crop. Similarly, latent heat flux (LE) ranged between 2.11 to $12.79 \mathrm{MJm}^{-2} d^{-1}$ during the crop season. In the present study in different phenological stages of wheat, latent heat flux varied between 3.59 to $15.25 \mathrm{MJm}^{-2} \mathrm{~d}^{-1}$. The ground heat flux varied from 0.31 to $0.88 \mathrm{MJm}^{-2} \mathrm{~d}^{-1}$ in different stages. The peak midday ground heat flux decreased gradually from crown root initiation to soft dough stage because of increasing soil coverage. It can be concluded from the present study that Bowen ratio approach is an efficient technique of measurement of energy balance. This method, as applied, can accurately estimate energy balance component for wheat crop in Tarai region of Uttarakhand.
\end{abstract}

Key word: Latent heat flux(LE), Phenological stages, Crown root initiation, Net radiation, Soft dough stage, BREB method

\section{Introduction}

Radiation and latent and sensible heating are among the most important processes in land-atmosphere exchanges. Hence, quantitative understanding and accurate estimation of these fluxes at large scales are imperative for research and applications in areas ranging from climate research, water cycle study, to water resources management, sustainable agricultural production and ecological conservation. The quantity and the form of energy available in a system determine the efficiency of the system. Available net radiation is the main source of energy in the earth system. Total energy available over a crop surface and partitioning of this into different components such as sensible heat (H), latent (LE) and soil heat fluxes (G) determine the crop production. Therefore, a thorough understanding of the radiation balance over a crop canopy and the accurate estimation of different components of net radiation over the crop surface assume a great significance in terrestrial ecosystem. The components of energy balance are calculated with the of help Bowen-ratio energy balance method and energy balance equation $\left(\mathrm{R}_{\mathrm{n}}+\mathrm{H}+\mathrm{LE}+\mathrm{G}+\mathrm{PS}+\mathrm{M}=0\right)$.

At field scale, Eddy covariance method (EC) and Bowen-ratio energy balance (BREB) are the two primary micrometeorological system used to measure surface scalar fluxes. EC provides direct measurement of sensible $(H)$ and latent heat fluxes $(\lambda E)$, whereas BREB is an indirect approach wherein $H$ and $(\lambda E)$ are calculated from other measurements and it is derived by combining with energy balance equation of the earth's surface (Tanner, 1960). This method has also been used to estimate energy (both latent as well as sensible parts) and mass (ET) fluxes, to quantify water use by crop (Cargnel $\boldsymbol{e t}$ al., 1996), to calculate crop coefficients (Malek and Bingham, 1993), to evaluate crop water models (Todd et al., 2000), and for measurement of emission of trace gases like methane and nitrous oxide etc., from the soil-crop surface, to measure carbon dioxide assimilate rate in crops (Chan et al., 1998) and energy balance studies above the crop surface (Hatfield, 1990 and Mokate et al., 1995).

\section{Material And Methods}

To evaluate the partioning of fluxes at different phenological Crown root initiation (CRI), tillering, jointing, heading, flowering, grain filling, soft dough and hard dough stages of wheat a micrmeteorological study was conducted in C6 block of the N. E. Borlaug Crop Research Centre of the G.B. Pant University of Agriculture and Technology, Pantnagar, (Uttarakhand), which is situated at $29^{\circ} \mathrm{N}$ latitude and $79.3^{0} \mathrm{E}$ longitudes. The area lies in "Tarai" belt located in foot hills of Himalaya. This area falls under sub-humid and 
sub tropical zone with three distinct season. The soil of experimental site belongs to Beni series with silty clay loam soil type (with Aquic Hapludoll). The size of experimental plot is $1 \times 1 \mathrm{~m}^{2}$ which is surrounded by wheat field having area of 1.4 ha. The sowing of wheat (PBW-343) seed was done by using tractor operated furrow opener cum seed drill. Fertilization and irrigation were applied as per the recommended package of practices. The objective of present study was to determine partitioning of energy fluxes at different phenological stages of wheat.

For demarcation of different phonological stages in each plot 10 plants were selected 10 days after emergence. They were tagged and future observations were carried out on the same plants. In case of disease attack to a plant or mechanical damage, the plant were substituted with another plant bearing growth and development of average plants of entire field. $10 \%$ of plant in a particular phase considered that phase has set in and $75 \%$ level indicates the phase completion. Based on visual plant observations at two to three days interval the occurrence of various phenological events of wheat, nine important phenological events viz. Crown root initiation (CRI), tillering, jointing, heading, flowering, grain filling, soft dough and hard dough stage were demarcated.

Estimation of Bowen ratio : Bowen-ratio( $\beta$ ) is estimated with the actual vapour pressure and temperature data at two different height i.e. at $1 \mathrm{~m}$ and $2 \mathrm{~m}$ height then Bowen-ratio $\beta$ were estimated with the help of following equation:

$$
\beta=\frac{\mathrm{H}}{\mathrm{LE}}=\gamma\left(\frac{\mathrm{kh}}{\mathrm{kw})}\right) \frac{\delta \mathrm{T}}{\delta \mathrm{e}}
$$

$\mathrm{kh}$ and kw are turbulent exchange coefficient for heat and water vapour transport respectively. $\gamma=\frac{\mathrm{PCp}}{\mathrm{L} \epsilon} \quad$ is Psychrometric constant, $\mathrm{Cp}=$ specific heat at constant pressure $\left(1008 \mathrm{~J} / \mathrm{Kg} /{ }^{\circ} \mathrm{C}\right), \mathrm{L}=$ Latent heat of evaporation $\left(2.43 \times 10^{6} \mathrm{~J} / \mathrm{kg}\right), €=$ Ratio of molecular weight of water and molecular weight of air $(0.622), \delta \mathrm{T}$ and $\delta \mathrm{e}=$ temperature and vapour pressure gradient respectively.

\section{Estimation of energy balance components} expressed as

For the calculation of latent heat flux and sensible heat flux energy balance equation was used which is

$$
\mathrm{R}_{\mathrm{n}}+\mathrm{H}+\mathrm{LE}+\mathrm{G}+\mathrm{PS}+\mathrm{M}=0
$$

Where $\mathbf{R}_{\mathbf{n}}=$ Net radiation, $\mathbf{H}=$ Sensible heat flux, $\mathbf{L E}=$ Latent heat flux, $\mathbf{G}=$ Ground heat flux, $\mathbf{P S}$ and $\mathbf{M}$ are energy fluxes in plants by photosynthesis and energy involved in respiration, respectively, which are assumed negligible due to its minor contribution (about $1-2 \%$ of Rn).

In the present study, Rn was calculated as

$$
\mathrm{Rn}=\mathrm{Rns}-\mathrm{Rnl}
$$

where, Rns = the net incoming short wave solar radiation, Rnl $\quad=$ the net long wave radiation. For measurement of Rns the formula given by Frtiz and MacDonald (1994) was used

$$
\mathrm{Rns}=\operatorname{Ra}(0.35+0.61 \mathrm{n} / \mathrm{N}) \quad \ldots(4)
$$

where, $\mathrm{Ra}=$ Extra-terresterial radiation $(\mathrm{mm} /$ day), $\mathrm{n} / \mathrm{N}=$ ratio between actual duration of bright sunshine hour(n) to maximum possible duration of bright sunshine $\mathrm{hr}(\mathrm{N})$ and $\mathrm{Rnl}$ is calculated as

$$
\mathrm{Rnl}=\mathrm{f}(\mathrm{T}) * \mathrm{f}(\mathrm{n} / \mathrm{N}) * \mathrm{f}(\mathrm{ed})
$$

Where, $f(T)=$ function of temperature, $f(e d)=$ function of actual vapour pressure, $f(n / N)=$ function of $(n / N)$ . Ground heat flux $(\mathrm{G})$ was calculated with the help of formula which is as follows

$$
\mathrm{G}=\mathrm{Cs} \frac{\mathrm{Ti}-\mathrm{Ti}-1}{\Delta \mathrm{t}} \Delta \mathrm{z}
$$

where, $\mathrm{G}=$ soil heat flux $\left(\mathrm{Mj} / \mathrm{m}^{2} /\right.$ day $), \mathrm{Cs}=$ soil heat capacity $\left(\mathrm{Mj} / \mathrm{m}^{2} / 0 \mathrm{c}\right), \mathrm{Ti}=$ air temperature at time $\mathrm{i}\left({ }^{0} \mathrm{C}\right), \mathrm{Ti}-$ $1=$ air temperature at $\mathrm{i}-1\left({ }^{0} \mathrm{C}\right), \Delta \mathrm{t}=$ length of time interval (day), $\Delta \mathrm{z}=$ effective soil depth. Latent heat flux was calculated with the help of equation (1), $\beta$ can be expressed as an ratio between latent and sensible heat flux.

Therefore, $\mathrm{H}=\beta$. LE , LE $=-\left(\frac{\mathrm{Rn}+\mathrm{G}}{1+\beta}\right), \mathrm{LE}=-\left(\frac{\mathrm{Rn}+\mathrm{G}}{1+\frac{\delta \mathrm{T}}{\mathrm{\delta e}}}\right)$

\section{Result And Discussion}

The diurnal pattern of important weather parameter (temperature and vapour pressure deficit) during rabi season of 2012-13 has bee shown in (Fig.1.1). In the present study, the values of Bowen ratio ( $\beta$ ) were positive throughout the crop season (Table 1.1) and ranged between 0.16 to 0.14 . During emergence the value of $\beta$ was low (0.16) due to application of irrigation two days before sowing. However it was relatively higher (1.14) at hard dough stage .In situations when $\beta$ is greater than unity, more amount of energy is partitioned in to sensible heat than the latent heat meaning more energy is dissipated into the atmosphere as sensible heat rather than latent heat from the surface (Neog et al., 2005). The net radiation and its partitioned component into sensible heat flux $(\mathrm{H})$, latent heat flux (LE) and ground heat flux $(\mathrm{G})$ at different stages of wheat are illustrated in the figure(1.2), while its ratio and leaf area index (LAI) at different stages are given in Table (1.2). The result 
showed that net radiation $(\mathrm{Rn})$ was major component of energy balance range which varied between 6.02 to 27.6 MJm-2d-1.Table (1.3), which represent the total available energy. Sensible heat found to ranged between 2.11 to 12.79 MJm-2d-1during the crop season. At crown root initiation and tillering stages 59.6 to 64.1 per cent of Rn was consumed in latent heat flux, while 29.4 to 35 per cent was partitioned in to sensible heat flux (Table 1.3). It is found that at crown root initiation and tillering stages59.6 to 64.1 per cent of $\mathrm{Rn}$ was consumed in latent heat flux, while 29.4 to 35 per cent was partitioned in to sensible heat flux (Table 4.6). At soft dough and hard dough stages sensible heat flux was 37.7 and 46.3 per cent of net radiation, respectively and directed away from the surface. The latent heat flux on day of observation at jointing, flowering, soft dough and hard dough stages were $73.6,74,62.2$ and 50.3 per cent of net radiation, respectively. It can be seen from the above results that, during later part of the growth stages LE is decreasing, its either because of decrease in area of major transpiring surface (leaf area) or increase in ambient temperature during later stages of growth. This resulted finally in increasing vapour pressure deficit, and increase in proportion of sensible heat flux at hard dough stage. Similar results were reported by Johnson $\boldsymbol{e t}$ al. (1977), who found high LE at hard dough stage of wheat. In another instance, LE was about 92 per cent of net radiation under favourable soil moisture conditions and it was about 62 per cent of Rn for wheat in dry conditions (Brun et al., 1985). The $\frac{L E}{R n}$ ratio increased from 0.59 at crown root initiation stage to 0.81 at flowering stage and decreased thereafter. However, Aese and Siddoway (1982) found that $\frac{L E}{R n}$ ratio for wheat crop was above 1.0 till harvest for semiarid climate. Blad and Rosenberg (1974) reported that the BREB method underestimated LE under conditions of regional sensible heat advection. They suggested that the underestimation is due to an inequality in $\mathrm{Kh}$ and $\mathrm{Kw}$. Later studies by Verma et al. (1978) have shown that $\mathrm{Kh}$ is greater than $\mathrm{Kw}$, when conditions of regional sensible heat advection prevails. Estimation of LE with Bowen ratio method in regions of sensible heat advection will be improved by using actual $\mathrm{Kh} / \mathrm{Kw}$ ratios rather than the assumption that $\mathrm{Kh} / \mathrm{Kw}=1$.

\section{Conclusion}

Therefore, it is concluded from the present study that Bowen ratio approach is an efficient technique of measurement of energy balance components. This method, as applied, can accurately estimate partitioning of energy balance component for wheat in Tarai region of Uttarakhand. Of the meteorological methods of quantifying evaporative flux density, the Bowen ratio offers the benefits of measuring parameters exclusively above the surface, (although soil heat flux density needs to be quantified below the surface). The advantage of this method is that it requires none of the difficult surface measurements used by other aerodynamic methods. Thus successful implementation of the method can be implemented for smaller areas . Data generated in the present study will be useful to validate evapotranspiration models. Future studies are needed to examine how canopy size, crop type, and plant water stress affect soil and canopy energy balances

\section{Acknowledgment}

It is a pleasure to thank and acknowledge Dr. Sumana Roy, Assistant Professor, of Agrometeorology for her inspiring guidance and encouragement. I am also thankful to my respected senior Dr. Harshvardhan Puranik for his cooperation for to do this work.

\section{References}

[1]. Tanner, C.B. 1960. Energy balance approach to evapotranspiration from crops. Soil Sci. Am. Proc. 24: 545-549.

[2]. Tanner, C.B. 1960. Energy balance approach to evapotranspiration from crops. Soil Sci. Am. Proc. 24: 545-549.

[3]. Malek, E. and Bingham, G.E. 1993. Comparison of the Bowen ratio-energy balance and the water balance methods for the measurement of evapotranspiration. J. Hydro/. 146: 209-220.

[4]. Todd, R.W., Evett, S.R. and Howell, T.A. 2000. The Bowen-ratio-energy balance method for estimating latent heat flux of irrigated alfalfa evaluated in semi arid, advective environment. Agric. For. Met. 103: 335-348.

[5]. Chan, S., Chen, J., Lin, G., Zhang, W., Miao, H., Wei, L., Huang, J. and Han, X. 1998. Energy balance and partition in Inner Mongolia steppe ecosystems with different land use types. Agric. For. Met. 149:1800-1809.

[6]. Hatfield, J.L. 1990. Methods of estimating evapotranspiration. P. 435-474. In B.A. Stewart and D.R. Nielsen (ed.) Irrigation of agricultural crops.Agron Monogr. 30. ASA, CSSA, Madison.

[7]. Fritz, S. and Mac Donald, J.H. 1949. Average solar radiation in the United states. Heating and Ventillating, $46: 61-64$.

[8]. Jhonson, R. 1977. A comparison of two methods for estimating sensible heat flux in oceanic extratropical synoptic scale. Tellus, 29: 222-228.

[9]. Brun, D. and Beverly, E.L. 1985. On measuring energy fluxes above the floor of a homogeneous and heterogeneous conifer forest.

[10]. Aese, J.K. and Siddoway, F.H. 1982. Evaporative flux from wheat and fallow in semi arid climate. Soil Sci. Soc. Amer. J. 46:619626.

[11]. Blad, B. L. and Rosenberg, N.J. 1974. Lysimetric calibration of the Bowen Ratio, Energy Balance method for evapotranspiration estimation in central Great. Appl. Meteorol. 13:227-236.

[12]. Verma, S. B., Rosenberg, N.J. and Blad, B.L.1978. Turbulent exchange coefficients for sensible heat and water vapour under adjective conditions. J. Appl. Meteorol. 17:330-338

[13]. Luchiari, A., Riha, S.J. and Gomide, R.L. 1997. Energy balance in irrigated wheat in the cerrados region of central piraciaba. Sci. Agri. 54: 78-88. 
[14]. Mokate, A.S., Varshneya. M.C. Naidu, T.R.V and Sadani, L.K. 1995. Evapotranspiration and energy balance studies over wheat crop by Bowen ratio energy balance method. J. Mah. Agric Univ. 20(2):273-276

[15]. Neog, P. Srivastava, A.K. and Chakravarty, N.V.K. 2005. Estimation and Application of Bowen Ratio Fluxes over Crop Surfaces An Overview Jour. Agric. Physics, 5:36-45.

Table 1.1: Bowen-ratio values at different phenological stages of wheat.

\begin{tabular}{|l|l|l|}
\hline Sl. No. & Growth stage & 及 \\
\hline 1 & Emergence & 0.16 \\
\hline 2 & CRI & 0.37 \\
\hline 3 & Tillering & 0.46 \\
\hline 4 & jointing & 0.27 \\
\hline 5 & Heading & 0.45 \\
\hline 6 & Flowering & 0.20 \\
\hline 7 & Grain filling & 0.28 \\
\hline 8 & Soft dough stage & 0.60 \\
\hline 9 & Hard dough stage & 1.14 \\
\hline
\end{tabular}
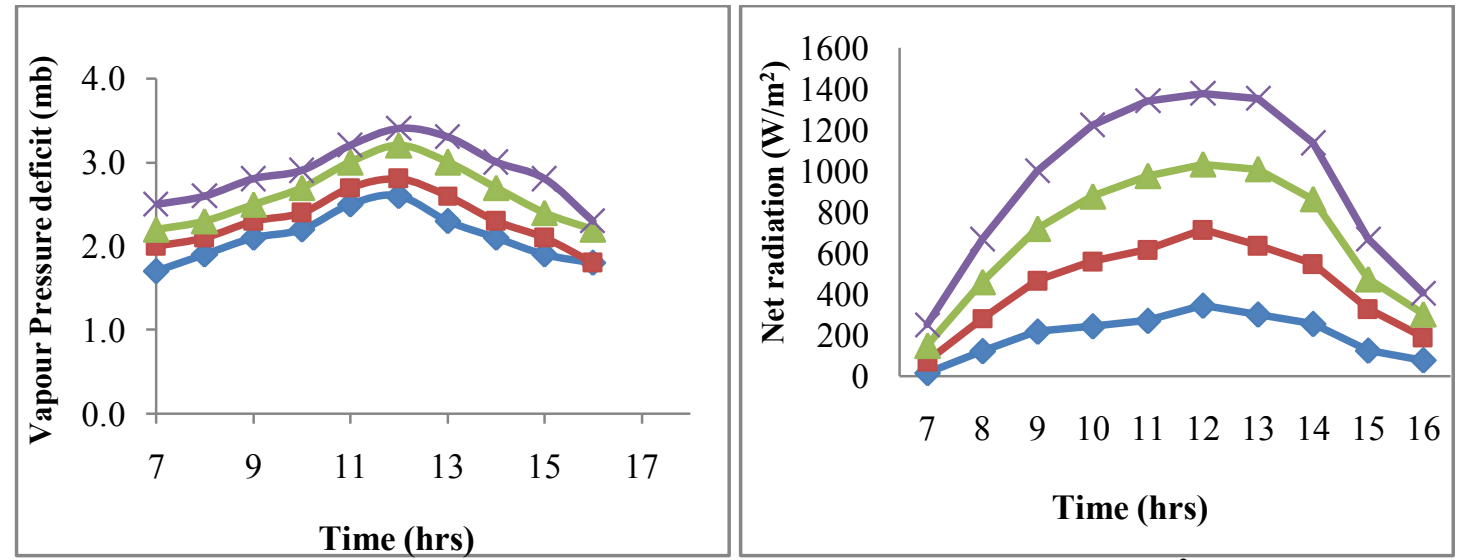

Fig. 1.1: Diurnal variation of VPD (mb), Net radiation $\left(\mathrm{W} / \mathrm{m}^{2}\right)$

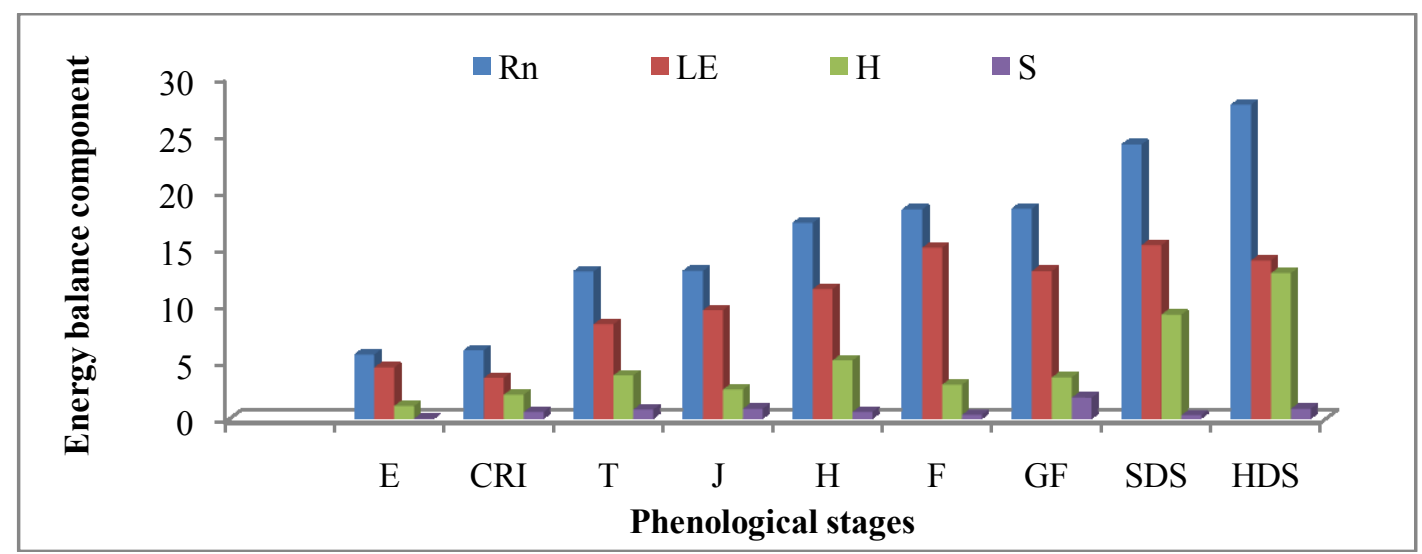

Fig. 1.2: Partioning of energy balance component at different phonological stages of wheat 
Table 1.2: $\quad$ Percent of sensible heat $(H)$,latent heat(LE) and ground heat $(G)$ relative to net radiation(Rn) durig rabi $2012-13$.

\begin{tabular}{|l|l|l|l|l|}
\hline \multirow{2}{*}{ Growth stage } & $\mathbf{M J} / \mathbf{m}^{\mathbf{2} / \mathbf{d a y}}$ & $\mathbf{\%} \mathbf{H}$ & $\mathbf{\% L E}$ & $\mathbf{\%} \mathbf{G}$ \\
\cline { 2 - 6 } & $\mathbf{R n}$ & 32 & 58.6 & 9.4 \\
\hline CRI & 6.02 & 29.4 & 64.1 & 6.5 \\
\hline Tillering & 12.94 & 19.7 & 73.6 & 6.7 \\
\hline Jointing & 13 & 29.8 & 66.4 & 3.8 \\
\hline Heading & 17.2 & 16 & 74.0 & 10 \\
\hline Flowering & 18.4 & 20.6 & 78.2 & \\
\hline Grain-filling & 18.46 & 37.7 & 62.2 & \\
\hline Soft-dough stage & 24.1 & 46.3 & 50.3 & 0.1 \\
\hline Hard-dough stage & 27.6 & & 3.4 \\
\hline
\end{tabular}

Table 1.3: $\quad$ Energy balance components and their partitioning relative to net radiation (Rn) at various growth stages of wheat

\begin{tabular}{|c|c|c|c|c|c|}
\hline \multirow{2}{*}{ Growth stage } & \multicolumn{5}{|c|}{$\mathrm{MJ} / \mathrm{m}^{2} / \mathrm{day}$} \\
\hline & Rn & LE/Rn & G/Rn & H/Rn & LAI \\
\hline CRI & 6.02 & 0.59 & 0.09 & 0.35 & 0.72 \\
\hline Tillering & 12.94 & 0.64 & 0.06 & 0.29 & 2.66 \\
\hline Jointing & 13 & 0.73 & 0.06 & 0.19 & 2.29 \\
\hline Heading & 17.2 & 0.66 & 0.03 & 0.29 & 3.5 \\
\hline Flowering & 18.4 & 0.81 & 0.01 & 0.16 & 3.13 \\
\hline Grain-filling & 18.46 & 0.70 & 0.1 & 0.19 & 1.88 \\
\hline Soft-dough stage & 24.1 & 0.63 & 0.001 & 0.37 & 1.6 \\
\hline Hard-dough stage & 27.6 & 0.50 & 0.03 & 0.46 & 1.1 \\
\hline
\end{tabular}

